\title{
Rehabilitation Outcomes in C6 Tetraplegia
}

\author{
G. M. Yarkony, MD, E. J. Roth, MD, A. W. Heinemann, PhD, \\ L. Lovell, BS \\ Midwest Regional Spinal Cord Injury Care System, Department of Rehabilitation \\ Medicine, Rehabilitation Institute of Chicago, Northwestern University Medical \\ School, Chicago, Illinois 60611, USA.
}

\begin{abstract}
Summary
This study reports on the rehabilitation outcome of 69 C6 tetraplegic patients admitted to the Rehabilitation Institute of Chicago during an 8 year period. All patients' last normal level was C6 bilaterally. A 100-point modified Barthel Index was used to obtain measures of functional independence in 15 self-care and mobility tasks. The population consisted of 54 males and 15 females with an average age of 29.2 years. The average number of days from injury to admission to the rehabilitation unit was 58.6 and the average length of rehabilitation stay was 108.4 days. The average Modified Barthel Index score increased from 16.6 on admission to $50 \cdot 1$ on discharge. The Self-Care Subscore increased from $12 \cdot 8$ to $32 \cdot 2$ and the Mobility subscore from $3 \cdot 7$ to 17.9. There were statistically significant increases in the number of patients able to perform all tasks except ability to don an orthosis and ability to walk 50 yards. This study documents a significant increase in function of C6 spinal cord injured patients during rehabilitation.
\end{abstract}

Key words: Spinal cord injury; Tetraplegia; Rehabilitation; Rehabilitation centres.

Rehabilitation of the spinal cord injury (SCI) patient from time of injury to hospital discharge is aimed at maximising functional independence and preventing medical complications. Although multiple factors affect the ultimate performance of an individual patient, many authors, including Bedbrook (1980), have stated that the neurological level of the lesion of the spinal cord lesion is the primary determinant of the degree of physical limitation.

Sverdlik and Rusk (1950) described a series of 23 tetraplegic patients who underwent rehabilitation. They asserted that modern techniques of rehabilitation made the prevalent attitudes of hopelessness and futility for the tetraplegic patient unjustified. Since that time, several authors have described SCI rehabilitation techniques, and have based optimal functional expectations for spinal cord injured 
patients on the neurological level of the lesion. Long and Lawton (1955) reported the functional significance of each spinal cord segmental level and stated that muscle power was the most important factor. They reported that C6 tetraplegic patients were able to feed with assistive devices, type on a typewriter, propel a wheel chair on level surfaces, and assist with rolling in bed, but required attendants for transfers, toileting, and dressing. Their discussion was limited to the 'average patient', and they noted that great individual differences existed. Symington and Mackay (1966), in describing the functional outcomes of 12 tetraplegic patients, concluded that prompt referral of patients to spinal cord injury centres and specialised rehabilitation facilities effected substantial savings and lower complication rates. Bromley (1981) studied a group of 66 C6 quadriplegic patients, and noted that this level of injury was one in which patients could reach a greater degree of independence than previously believed. Training in dressing was found to benefit $88^{\circ}{ }_{0}$ of patients and training in transfers $60^{\circ}{ }_{0}$ of patients. Finally, the rehabilitation outcomes of 100 SCI patients were studied by Woolsey (1985), who found that most of the 19 C6 tetraplegic patients in his group required assistance for bowel management, bladder care, and transferring, but were otherwise independent. He noted that Long and Lawton's (1955) outline of functional activities was derived from a theoretical formulation of useful muscle power, rather than from actual patients experience.

Because of the numerous complexities of rehabilitation and the variety of functional activities which disabled patients perform, a number of rehabilitation outcome measures have been described. Mahoney and Barthel (1965) proposed the Barthel Index as a means of scoring status and improvement during rehabilitation. It was composed of 10 outcome ratings of self-care and mobility skills. Granger, et al. (1979), using a modified version of this Index, rated ability to perform 15 skills and showed that the Barthel Index could be used to describe individual and group progress in rehabilitation. It also is used to evaluate treatment effectiveness and to describe specific functional expectations as aids to planning rehabilitation programs. Granger, et al. (1979) demonstrated that the Barthel Index was a valid reliable, and sensitive measure of functional abilities and change in performance over time. The present investigation was undertaken to describe the functional outcomes of a large series of patients with C6 tetraplegia, using the 100-point modified Barthel Index, in order to provide general guidelines for rehabilitation outcomes in spinal cord injured patients and to document the functional benefits of rehabilitation in these individuals.

\section{Materials and methods}

The medical records of 69 C6 tetraplegic patients admitted to the Rehabilitation Institute of Chicago during an 8-year period (1973-1980) were reviewed. Only patients for whom the lowest normal motor level was C6 bilaterally were studied. Thus, patients had normal deltoid, biceps, and radial wrist extensor strength. A complete lesion was defined as one with no sensory or motor function below the level of spinal injury; an incomplete lesion was defined as a lesion with any sensory or motor function below the level of spinal injury.

Demographic data, including age, sex, race, educational level, and injury 
characteristics, including completeness and etiology, were recorded, as were duration from injury to rehabilitation and length of rehabilitation stay. A modified Barthel Index (MBI) was scored for each patient at rehabilitation admission and discharge. This index rated degree of independence in 15 selfcare and mobility skills (Yarkony, et al., 1987), and has been found to be a valid and reliable measure of functional abilities (Granger et al., 1979).

On the MBI scale, independence in a task was defined as the ability to perform the activity without involving another person. The patient may have used an appliance, brace or a splint (orthoses). Assistance was defined as performance of at least half the effort for the task; the assistant provided lifting, guarding, spotting, supervising or queuing. Dependence identified ability to perform less than half the effort of the task, or total inability to perform the task. The MBI had a maximum possible score of 100 points, and was divided into two Subscores. The scoring of the Self Care Subscore was as follows. A person who was independent in drinking from a cup ( 4 points) was able to drink from a cup at a tray or table, pour liquids and open a milk carton. Assistance in drinking from a cup ( 2 points) required having the liquid poured, using a straw, or performing the skill in more than a reasonable time period. Independence in feeding 6 points) required the ability to cut meat, butter bread, and eat from a customarily prepared meal tray. Assistance in feeding ( 3 points) was defined as requiring help for cutting meat or buttering bread, using an assistive device, or requiring prolonged time. Independence in dressing upper body (5 points) or lower body (7 points), included obtaining clothes from their customary places, handling pullover and front opening garments and managing buttons and snaps. Assistance in dressing upper body ( 3 points) or lower body ( 4 points) required retrieval or arrangement of clothes by an assistant, use of special closures or a prolonged time period. Ability to don a brace independently ( 0 points) required performance with reasonable ease; otherwise, this task was scored as dependent $(-2$ points). Independence in grooming ( 5 points) required ability to clean teeth, brush hair, shave or apply makeup. Assistance in grooming (3 points) required use of assistive device or more than reasonable time. Independence in bathing ( 6 points) included the ability to wash and dry the face and body. Assistance in bathing ( 3 points) was defined as use of an assistive device or more than reasonable time. Reasonable time was defined by comparison with the time the patient required to perform these tasks prior to injury.

The last two Self-Care Subscore components, bladder and bowel functions, were divided into four categories of ability. Independence in bladder continence (10 points) was defined as complete voluntary elective control. Limited independence ( 8 points) allowed use of a catheter or collecting device, if managed independently by the patient, with no accidents. Assistance in bladder continence ( 5 points) was defined as need for assistance with external devices, occasional accidents or inability to wait for use of bedpan or toilet. Independence in bowel continence (10 points) was defined as complete voluntary continence. Limited independence ( 8 points) described an individual who managed bowel function on his own but required modifications from pre injury functioning such as use of stool softeners, enemas, digital stimulation, suppositories or laxatives, without assistance or accidents. Assistance in bowel function (5 points) was defined as having occasional accidents or requiring assistance with suppository or enema. 
The Mobility Subscore was scored as follows. Independence in chair transfers (15 points) required ability to approach, sit down, and arise from a chair safely, and included safe management of the wheelchair. Assistance ( 7 points) was defined as the requirement for lifting, transfer board or mechanical lift use, or prolonged time. Independence in toilet transfers ( 6 points) required an independent safe transfer. Assistance in toilet transfers ( 3 points) was defined as use of grab-bars or prolonged time for transfer. An independent tub transfer (1 point) required the ability to enter or leave the tub safely. Dependence in tub transfers (0 points) meant use of grab-bars, a special seat or prolonged time. Ability to walk independently ( 15 points) on a level 50 yards was defined as ability to walk this distance with or without an assistive device, and to stand and sit independently. Assistance for walking on a level 50 yards (10 points) was defined as the need for assistance, or supervision for safety. Independence with stairs (10 points) was defined as ability to go up and down at least one flight without any support. Assistance with stairs (5 points) was defined as ability to go up and down one flight by using a cane, handrails, assistance or supervision. Five points was scored for independence in the use of a wheelchair for 50 yards, if not walking. It required the ability to go around corners, turn around, manoeuvre to a chair, table, or toilet, and negotiate doorsills and a small grade. Dependence in all tasks was scored as zero. The Modified Barthel Index is described in Table 1.

In our system of SCI care, patients were admitted to our SCI acute care unit at Northwestern Memorial Hospital and then to the Rehabilitation Institute of Chicago (RIC), or directly to our rehabilitation unit at RIC from local hospitals without specialised spinal cord units. The MBI scores were recorded at the time of admission to RIC from either acute care setting and again at the time of discharge from RIC. In this way, the impact of rehabilitation was studied after medical stability was obtained and the patient was assessed ready for rehabili-

Table I Scoring of the modified Barthel Index

\begin{tabular}{|c|c|c|c|}
\hline Item & Independence & Assistance & Dependence \\
\hline \multicolumn{4}{|l|}{ Self-care subscore } \\
\hline Drinking from cup & 4 & 2 & 0 \\
\hline Eating & 6 & 3 & 0 \\
\hline Dressing upper body & 5 & 3 & 0 \\
\hline Dressing lower body & 7 & 4 & 0 \\
\hline Don brace or prosthesis & 0 & -2 & 0 \\
\hline Grooming & 5 & 3 & 0 \\
\hline Washing or bathing & 6 & 3 & 0 \\
\hline Bladder continence & 10 & $8+/ 5$ & 0 \\
\hline Bowel continence & 10 & $8+/ 5$ & 0 \\
\hline \multicolumn{4}{|l|}{ Mobility subscore } \\
\hline Transfer, chair & 15 & 7 & 0 \\
\hline Transfer, toilet & 6 & 3 & 0 \\
\hline Transfer, tub or shower & 1 & 0 & 0 \\
\hline Walk on level, $50 \mathrm{yd}$ & 15 & 10 & 0 \\
\hline Up and down stairs, one flight & 10 & 5 & 0 \\
\hline Wheelchair, $50 \mathrm{yd}$ (only if not walking) & 5 & 0 & 0 \\
\hline
\end{tabular}

†'Limited independence' in bowel and bladder continence scored 8 points each. 
tation. For patients who had rehabilitation hospitalisations interrupted by transfer to acute care facilities for management of acute medical complications, MBI scores were rated at definitive RIC discharge.

Statistical analysis was performed using two methods, Chi square and McNemar's test. Chi square testing assumes independent proportions in each category of the Barthel score. McNemar's test does not allow for analysis of improvements between the various outcome groups in the Barthel. McNemar's test allows for only two classifications to be analysed independent and not independent. Use of McNemar's test therefore did not allow analysis of improvements from dependent to assistance. Chi square values are presented in the tables with the degrees of freedom in parenthesis adjacent to the chi square values.

\section{Results}

The sample of 69 patients included 54 males, and the average age was 29.2 (Median 25.0) years (SD-15.8). The 69 patients ages ranged from 12 to 88 years. Twenty-one patients were 11-20 years old, 27 were 21-30 years old, 8 were 31-40 years old, 5 were 41-50 years old, 4 were 51-60 years old, and 3 were older than 61 years. Forty-seven patients were white, 19 black, and 3 hispanic. Forty-nine per cent had an eleventh grade education or less. Twenty per cent completed high school or had an equivalency diplomy, $19^{\circ}$ o had some college and $9^{\circ}{ }_{0}$ had an associates or bachelors degree.

Fifty-four per cent of the total sample had incomplete lesions and all had C6 as the most caudal normal motor level bilaterally. The most common causes of injury were auto accidents $\left(42^{\circ}{ }_{0}\right)$, diving $\left(25^{\circ}{ }_{0}\right)$ and falls $\left(17^{\circ}\right)$. Gunshot wounds accounted for $7^{\circ}$, followed by other sports injuries $(3 \%)$, pedestrian accidents $\left(3^{\circ}\right)$, and assaults $\left(1^{\circ}{ }_{0}\right)$. The mean duration from injury to rehabilitation admission was 58.6 days (Median $=50$ ). The mean length of time between injury and rehabilitation discharge was 167 days $($ Median $=155$ ). The mean length of stay in the rehabilitation unit was 100 days (Median $=105$ ).

The mean total Modified Barthel Index score increased significantly for the entire sample from 16.4 to $50 \cdot 1$ ( $\mathrm{p}<0.001$ ). The Self-Care Subscore increased significantly from 12.8 to $32 \cdot 2$, and the Mobility Subscore from 3.7 to 17.9 $(\mathrm{p}<0.001)$. The proportions of patients independent in performance of each of the $15 \mathrm{MBI}$ component tasks on admission and discharge are listed in Table II. The proportions of patients able to perform 8 of the 9 self care tasks improved significantly $(\mathrm{p}<0.001)$; only ability to don a brace did not improve. The proportions of patients independent in each of the Mobility Subscore components tasks are listed in Table III. Mobility Subscore component activities showed statistically significant increases $(p<0.001)$ in the proportions of patients able to perform 4 of the 6 tasks; walking 50 yards did not show a significant increase, and improvement in ability to walk up and down one flight of stairs was significart at $(\mathrm{p}<0.05)$. McNemar's test for the entire sample showed improvement in all skills $(\mathrm{p}<0.001)$ except walking $(\mathrm{p}<0.125)$ and stair climbing $(\mathrm{p}<0 \cdot 25)$. 
Table II MBI 'Self-care' subscore ${ }^{\star \star}$ for all patients

\begin{tabular}{|c|c|c|c|c|c|c|c|c|c|c|c|c|c|c|c|c|c|c|}
\hline & \multicolumn{2}{|c|}{ Drink/cup } & \multicolumn{2}{|c|}{ Feed/dish } & \multicolumn{2}{|c|}{ Dress uppers } & \multicolumn{2}{|c|}{ Dress lowers } & \multicolumn{2}{|c|}{ Don brace } & \multicolumn{2}{|c|}{ Grooming } & \multicolumn{2}{|c|}{ Bathing } & \multicolumn{2}{|c|}{$\begin{array}{c}\text { Bladder } \\
\text { continence }\end{array}$} & \multicolumn{2}{|c|}{$\begin{array}{c}\text { Bowel } \\
\text { continence }\end{array}$} \\
\hline & A & $\mathrm{DC}$ & A & $\mathrm{DC}$ & A & $\mathrm{DC}$ & A & $\mathrm{DC}$ & A & DC & A & $\mathrm{DC}$ & A & $\mathrm{DC}$ & A & $\mathrm{DC}$ & A & $\mathrm{DC}$ \\
\hline Dependence & $\begin{array}{l}33 \cdot 3 \\
\star \star \star\end{array}$ & $1 \cdot 4$ & $\begin{array}{l}42 \cdot 0 \\
\star \star \star\end{array}$ & $2 \cdot 9$ & $\begin{array}{l}89 \cdot 9 \\
\star \star \star \star\end{array}$ & $14 \cdot 5$ & $\begin{array}{l}97 \cdot 1 \\
\star \star \star \star\end{array}$ & $39 \cdot 1$ & - & - & $66 \cdot 7$ & $8 \cdot 7$ & $75 \cdot 4$ & $13 \cdot 0$ & $4 \cdot 3$ & $2 \cdot 9$ & $66 \cdot 7$ & 10.1 \\
\hline $\begin{array}{l}\text { Assistance } \\
\text { Limited }\end{array}$ & $59 \cdot 4$ & $63 \cdot 8$ & $52 \cdot 2$ & $63 \cdot 8$ & $8 \cdot 7$ & $52 \cdot 2$ & $1 \cdot 4$ & $37 \cdot 7$ & 100 & 100 & $29 \cdot 0$ & $58 \cdot 0$ & $23 \cdot 2$ & $58 \cdot 0$ & $87 \cdot 0$ & $60 \cdot 9$ & $29 \cdot 0$ & 55.1 \\
\hline independence * & - & - & - & - & - & - & - & - & - & - & - & - & - & - & $1 \cdot 4$ & $18 \cdot 8$ & 0 & 14.5 \\
\hline Independence & $7 \cdot 2$ & $34 \cdot 8$ & $5 \cdot 8$ & $33 \cdot 3$ & $1 \cdot 4$ & $33 \cdot 3$ & $1 \cdot 4$ & $23 \cdot 2$ & - & - & $4 \cdot 3$ & $33 \cdot 3$ & $1 \cdot 4$ & $29 \cdot 0$ & $7 \cdot 2$ & $17 \cdot 4$ & $4 \cdot 3$ & 20.3 \\
\hline $\begin{array}{l}\text { Chi square }(\mathrm{df}) \\
P\end{array}$ & \multicolumn{2}{|c|}{ (2) $32 \cdot 7$} & \multicolumn{2}{|c|}{ (2) $37 \cdot 7$} & \multicolumn{2}{|c|}{ (2) $79 \cdot 2$} & \multicolumn{2}{|c|}{ (2) $53 \cdot 4$} & \multicolumn{2}{|c|}{ N.S. } & \multicolumn{2}{|c|}{ (2) $52 \cdot 8$} & \multicolumn{2}{|c|}{ (2) $57 \cdot 8$} & \multicolumn{2}{|c|}{ (3) $16 \cdot 5$} & \multicolumn{2}{|c|}{ (3) $51 \cdot 4$} \\
\hline
\end{tabular}

$\star$ Bowel and bladder only.

$\star \star$ Given in percentages.

$\star \star \star$ Assistance $=$ Independent with tray provided, meat cut, beverages poured

$\star \star \star \star$ Asistance $=$ independent with clothes provided.

Table IIA MBI 'Self-care' subscore ${ }^{\star}$ for patients with complete C6 SCI

\begin{tabular}{|c|c|c|c|c|c|c|c|c|c|c|c|c|c|c|c|c|c|c|}
\hline & \multicolumn{2}{|c|}{ Drink cup } & \multicolumn{2}{|c|}{ Feed/dish } & \multicolumn{2}{|c|}{ Dress uppers } & \multicolumn{2}{|c|}{ Dress lowers } & \multicolumn{2}{|c|}{ Don brace } & \multicolumn{2}{|c|}{ Grooming } & \multicolumn{2}{|c|}{ Bathing } & \multicolumn{2}{|c|}{$\begin{array}{c}\text { Bladder } \\
\text { continence }\end{array}$} & \multicolumn{2}{|c|}{$\begin{array}{c}\text { Bowel } \\
\text { continence }\end{array}$} \\
\hline & A & DC & A & DC & A & $\mathrm{DC}$ & A & $\mathrm{DC}$ & $\mathrm{A}$ & $\mathrm{DC}$ & A & $\mathrm{DC}$ & A & $\mathrm{DC}$ & A & $\mathrm{DC}$ & A & $\mathrm{DC}$ \\
\hline Dependence & $\begin{array}{l}46 \cdot 9 \\
\star \star \star\end{array}$ & $3 \cdot 1$ & $\begin{array}{l}62.5 \\
\star \star \star\end{array}$ & $6 \cdot 3$ & $\begin{array}{l}93 \cdot 8 \\
\star \star \star \star\end{array}$ & $18 \cdot 8$ & $\underset{\star \star \star \star \star}{100}$ & $46 \cdot 9$ & 0 & 0 & $90 \cdot 6$ & $15 \cdot 6$ & $90 \cdot 6$ & $25 \cdot 0$ & $9 \cdot 4$ & $6 \cdot 3$ & $71 \cdot 9$ & $15 \cdot 6$ \\
\hline $\begin{array}{l}\text { Assistance } \\
\text { Limited }\end{array}$ & $53 \cdot 1$ & $78 \cdot 1$ & 37.5 & $78 \cdot 1$ & $6 \cdot 3$ & $68 \cdot 8$ & 0 & 50 & 100 & 100 & $9 \cdot 4$ & $65 \cdot 6$ & $9 \cdot 4$ & $65 \cdot 6$ & $90 \cdot 6$ & $78 \cdot 1$ & $28 \cdot 1$ & $68 \cdot 8$ \\
\hline independence ${ }^{\star}$ & - & - & - & - & 一 & - & - & - & - & - & - & - & - & - & 0 & $15 \cdot 6$ & 0 & $12 \cdot 5$ \\
\hline Independence & 0 & $18 \cdot 8$ & 0 & $15 \cdot 6$ & 0 & $12 \cdot 5$ & 0 & $3 \cdot 1$ & 0 & 0 & 0 & $18 \cdot 8$ & 0 & $9 \cdot 4$ & 0 & 0 & 0 & $3 \cdot 1$ \\
\hline $\begin{array}{l}\text { Chi square }(\mathrm{df}) \\
\mathrm{P}\end{array}$ & \multicolumn{2}{|c|}{ (2) $19 \cdot 8$} & \multicolumn{2}{|c|}{ (2) $24 \cdot 3$} & \multicolumn{2}{|c|}{ (2) $36 \cdot 7$} & \multicolumn{2}{|c|}{$\begin{array}{l}\text { (2) } 23 \cdot 1 \\
<0 \cdot 0001\end{array}$} & \multicolumn{2}{|c|}{ N.S. } & \multicolumn{2}{|c|}{$\begin{array}{l}\text { (2) } 36 \cdot 4 \\
<0.0001\end{array}$} & \multicolumn{2}{|c|}{$\begin{array}{l}\text { (2) } 28.4 \\
<0.0001\end{array}$} & \multicolumn{2}{|c|}{ N.S. } & \multicolumn{2}{|c|}{$\begin{array}{l}\text { (3) } 30 \cdot 8 \\
<0.0001\end{array}$} \\
\hline
\end{tabular}

$\star$ Bowel and bladder only.

$\star \star$ Given in percentages.

$\star \star \star$ Assistance $=$ Independent with tray provided, meat cut, beverages poured.

$\star \star \star \star$ Asistance $=$ independent with clothes provided. 
Table III MBI mobility subscore for all patients

\begin{tabular}{|c|c|c|c|c|c|c|c|c|c|c|c|c|c|}
\hline & \multicolumn{2}{|c|}{$\begin{array}{l}\text { Chair } \\
\text { transfer }\end{array}$} & \multicolumn{2}{|c|}{$\begin{array}{c}\text { Toilet } \\
\text { transfer }\end{array}$} & \multicolumn{2}{|c|}{$\begin{array}{c}\text { Tub } \\
\text { transfer }\end{array}$} & \multicolumn{2}{|c|}{$\begin{array}{c}\text { Walk } \\
50 \text { yards }\end{array}$} & \multicolumn{2}{|c|}{$\begin{array}{l}\text { Stairs } \\
1 \text { flight }\end{array}$} & \multicolumn{2}{|c|}{ Wheelchair } & \multirow{2}{*}{$\begin{array}{c}\text { Degree of } \\
\text { wheelchair } \\
\text { independence }\end{array}$} \\
\hline & A & $\mathrm{DC}$ & A & DC & A & $\mathrm{DC}$ & A & $\mathrm{DC}$ & A & $\mathrm{DC}$ & A & $\mathrm{DC}$ & \\
\hline Dependence & $81 \cdot 2$ & $18 \cdot 8$ & $95 \cdot 7$ & $40 \cdot 6$ & $98 \cdot 6$ & $72 \cdot 5$ & $97 \cdot 1$ & $82 \cdot 6$ & 100 & $84 \cdot 1$ & $2 \cdot 9$ & $17 \cdot 4$ & $\begin{array}{l}\text { Did not use } \\
\text { wheelchair }\end{array}$ \\
\hline Assistance & $15 \cdot 9$ & $49 \cdot 3$ & $1 \cdot 4$ & $30 \cdot 4$ & - & - & $2 \cdot 9$ & $11 \cdot 6$ & 0 & $11 \cdot 6$ & $63 \cdot 8$ & $10 \cdot 1$ & Dependent \\
\hline Independence & $2 \cdot 9$ & 31.9 & $2 \cdot 9$ & $29 \cdot 0$ & $1 \cdot 4$ & $27 \cdot 5$ & 0 & $5 \cdot 8$ & 0 & $4 \cdot 3$ & $33 \cdot 3$ & $72 \cdot 5$ & Independent \\
\hline Chi square $(\mathrm{df})$ & \multicolumn{2}{|c|}{ (2) $55 \cdot 2$} & \multicolumn{2}{|c|}{ (2) $48 \cdot 3$} & \multicolumn{2}{|c|}{ (1) $16 \cdot 9$} & \multicolumn{2}{|c|}{ (2) 8.4} & \multicolumn{2}{|c|}{ (2) 11.9} & \multicolumn{2}{|c|}{ (2) $45 \cdot 8$} & \\
\hline $\mathrm{P}$ & \multicolumn{2}{|c|}{$<0.0001$} & \multicolumn{2}{|c|}{$<0.0001$} & \multicolumn{2}{|c|}{$<0.0001$} & \multicolumn{2}{|c|}{$<0.05$} & \multicolumn{2}{|c|}{$<0.05$} & \multicolumn{2}{|c|}{$<0.0001$} & \\
\hline
\end{tabular}

Table IIIA MBI mobility subscore for patients with complete C6 SCI

\begin{tabular}{|c|c|c|c|c|c|c|c|c|c|c|c|c|c|}
\hline & \multicolumn{2}{|c|}{$\begin{array}{l}\text { Chair } \\
\text { transfer }\end{array}$} & \multicolumn{2}{|c|}{$\begin{array}{l}\text { Toilet } \\
\text { transfer }\end{array}$} & \multicolumn{2}{|c|}{$\begin{array}{c}\text { Tub } \\
\text { transfer }\end{array}$} & \multicolumn{2}{|c|}{$\begin{array}{c}\text { Walk } \\
50 \text { yards }\end{array}$} & \multicolumn{2}{|c|}{$\begin{array}{l}\text { Stairs } \\
1 \text { flight }\end{array}$} & \multicolumn{2}{|c|}{ Wheelchair } & \multirow{2}{*}{$\begin{array}{c}\text { Degree of } \\
\text { wheelchair } \\
\text { independence }\end{array}$} \\
\hline & A & DC & A & DC & A & DC & A & DC & A & DC & A & DC & \\
\hline Dependence & $93 \cdot 8$ & $31 \cdot 3$ & 100 & $56 \cdot 3$ & 100 & $93 \cdot 8$ & 100 & 100 & 100 & 100 & 0 & 0 & $\begin{array}{l}\text { Did not use } \\
\text { wheelchair }\end{array}$ \\
\hline Assistance & $6 \cdot 3$ & $62 \cdot 5$ & 0 & $37 \cdot 5$ & - & - & 0 & 0 & 0 & 0 & $87 \cdot 5$ & $12 \cdot 5$ & Dependent \\
\hline Independence & 0 & $6 \cdot 3$ & 0 & $6 \cdot 3$ & 0 & $6 \cdot 2$ & 0 & 0 & 0 & 0 & $12 \cdot 5$ & $87 \cdot 5$ & Independent \\
\hline $\begin{array}{l}\text { Chi square }(\mathrm{df}) \\
\mathrm{P}\end{array}$ & \multicolumn{2}{|c|}{ (2) $26 \cdot 7$} & \multicolumn{2}{|c|}{ (2) $17 \cdot 9$} & \multicolumn{2}{|c|}{ N.S. } & \multicolumn{2}{|c|}{ N.S. } & \multicolumn{2}{|c|}{ N.S. } & \multicolumn{2}{|c|}{ (1) 33} & \\
\hline
\end{tabular}


Separate analysis was performed to examine the functional abilities of the 32 patients with complete C6 tetraplegia. These patients demonstrated statistically significant increases $(p<0.001)$ in function during rehabilitation in the total MBI Score, the Self-Care Subscore, and the Mobility Subscore. The mean total MBI score increased from 9.9 to $37 \cdot 6$, the Self-Care Subscore from 8.8 to 26.2 and the Mobility Subscore from 1.1 to 11.5 . As illustrated in Table IIA, there were statistically significant improvements $(p<0.001)$ in the number of patients able to perform 7 or 9 tasks on the Self-Care Subscore; only ability to don a brace and bladder continence did not show significant increases. Table IIIA demonstrate that statistically significant increases $(\mathrm{p}<0.001)$ were present in the percentage of patients able to perform 4 of the 6 tasks on the Mobility Subscore; only ability to walk 50 yards and ability to climb one flight of stairs did not show significant changes. For the complete injuries McNemar's test showed significant improvements for grooming $(\mathrm{p}<0.05)$, drinking from a cup $(\mathrm{p}<0.05)$ and wheelchair propulsion $(\mathrm{p}<0.001)$.

\section{Discussion}

This study documents statistically significant improvement of function during rehabilitation in $69 \mathrm{C} 6$ tetraplegic patients using the modified Barthel Index. The Self-Care and Mobility Subscores, and most of the individual component tasks of these Subscores, improved significantly as well. These data can be used to serve as guidelines for the design and implementation of rehabilitation programmes for C6 SCI patients. Documentation of functional improvement during rehabilitation is of increasing importance as available funds for health care diminish. The decrease in dependency on others by tetraplegic patients demonstrated in this study helps to justify the efforts and expense of intensive, inpatient, multidisciplinary rehabilitation programmes. These conclusions are limited by the lack of a control group and the presence of patients from only one centre who gave informed consent during that time period. However, it does include a large sample of patients with patients denied admisson only if they were medically unstable and unable to participate in the programme. Improvement cannot be ascribed to time alone as the use of orthotic devices and a specially trained staff make similar improvements unlikely in this group of patients with limited motor function. A control group although important for the purposes of study cannot be justified due to the complex medical needs of these patients after acute care in areas such as bowel, bladder and skin care.

The typical C6 complete tetraplegic patient can be expected to eat and drink with food provided and dress with clothes provided. Patients at this level would also have a greater likelihood of doing more complex tasks such as cutting meat, buttering bread, pouring liquids and opening milk containers. The C6 tetraplegic patient can usually groom himself, assist with bathing, and may manage his own urinary drainage devices and perform his bowel programme independently. Transfers are usually with assistance, but exceptional patients can perform them independently. Wheelchair propulsion on both flat surfaces and inclines could be performed independently.

In comparison with the typical C5 complete tetraplegic patient (Yarkony, Roth, Lovell, et al, 1987), there is a greater level of independence in feeding, 
drinking, dressing, grooming, transferring, and wheelchair propulsion. The occasional C6 complete tetraplegic patient who is well-motivated and living in an accessible environment can live independently without assistance, but this is relatively unusual.

Such factors as motivation, physique, psychosocial status, and complications of spinal cord injury, play a major role in determining actual functional outcomes of patients. Although not addressed specifically, these factors may explain the varied outcomes of many of these patients.

\section{References}

BedBROOK G, SEDGLEy GI 1980 The management of spinal injuries-past and present. International Rehabilitation Medicine 2:45-61.

BROMLEY I 1981 Tetraplegia and paraplegia a guide for physiotherapists. Churchill Livingstone, Edinburgh p. 37-46.

Cummens CL, Haugh DM 1973 MRSCICS patient function determination procedure, notes and results. Rehabilitation Institute of Chicago, Chicago p. 1-10.

Granger CV, Albrecht GL, HAMilton BB 1979 Outcomes of comprehensive medical rehabilitation: measurement by pulses profile on the Barthel Index Archives of Physical Medicine Rehabilitation 60:145-154.

LoNG C, LAwTON EB 1955 Functional significance of spinal cord lesion level. Archives of Physical Medicine Rehabilitation 36:249-255.

MAHONEY FI, BARTHEL DW 1965 Functional evaluation: the Barthel Index Maryland State Medical fournal 14:61-65.

SVERDLIK SS, RUSH HA 1950 Rehabilitation of the quadriplegic patient fournal of American Medical Association 142:321-324.

SyNINGTON DC, MACKAY DE 1966 A study of functional independence in the quadriplegic patient Archives of Physical Medicine Rehabilitation 47:378-392.

WOOLSEY RM 1985 Rehabilitation outcome following spinal cord injury. Archives of Neurology 42:116-119.

YARKoNy GM, Roth EJ, HeINEMANN AW, et al. 1987 Benefits of rehabilitation in spinal cord injury; multivariate analysis in 711 patients. Archives of Neurology 44:93-96.

YaRKoNy GM, Roth E, Lovell L, et al. 1987 Rehabilitation Outcomes in 120 Patients with C5 Quadriplegia (Abs) Archives of Physical Medicine Rehabilitation 68:672. 